\title{
X-ray spectral microanalysis of X13 steel powders obtained by electroerosive dispersion
}

\author{
E. V. Ageeva ${ }^{1}, S . V$. Khardikov $^{1, *}$, and $A . N$. Novikov $^{2}$ \\ ${ }^{1}$ Southwest state University, 305040, Kursk, Russian Federation \\ ${ }^{2}$ OSU named after I. S. Turgenev, 302026, Orel, Russian Federation
}

\begin{abstract}
Chromium is the most common alloying element. Chromium alloyed steel has increased strength, hardness, wear resistance, corrosion resistance in aggressive and oxidizing environments. The process of obtaining powder materials by the method of electroerosion dispersion favorably differs by the possibility of obtaining powders even from very hard and refractory materials. In the case of grinding material with this method, the only important criterion is the electrical conductivity of the material being ground. Worn parts and other scrap can be used as feedstock during the process. The purpose of the study is to investigate the powder, obtained from the waste of chromium-containing steels. Thanks to the study of the used powder samples on modern devices, results were obtained indicating that the chromium powder obtained by the method of electroerosive dispersion can be reused to restore and strengthen the machine parts.
\end{abstract}

\section{Introduction}

Chromium is the main alloying element that makes stainless steel. When the content of chromium in steel is more than $12.5 \%$, a protective oxide film of $\mathrm{Cr}_{2} \mathrm{O}_{3}$ is formed on its surface [1-3]. Depending on the composition of stainless steels are divided into two main classes:

- chromic, having a ferritic, martensitic-ferritic or martensitic structure after air cooling;

- chromium-nickel, having austenitic, austenitic-martensitic or austenitic-ferritic structure.

These steels have a fairly good set of technological properties. The higher the chromium content, the higher the corrosion resistance of chromium steels. [4-6]

Iron with chromium forms a continuous series of solid solutions, so you can get steel with a high content of chromium in solid solution. Chromium is not a scarce metal, its cost is relatively low, so chromium steels are the cheapest stainless steels and therefore a large amount of their waste is generated. Therefore, there is an acute problem of recycling chromium-containing steel waste into powders suitable for practical use. The most promising method for processing such wastes is the electro-erosion dispersion method

\footnotetext{
* Corresponding author : hardikov1990@mail.ru
} 
(EED), which is distinguished by the ecological purity of the process and relatively low energy costs [7-10].

The widespread use of the method of EED for processing ball-bearing steel wastes into powders for the purpose of their reuse is hampered by the lack of complete information in the scientific and technical literature on the properties of powders and technologies of practical application. For the development of technologies for the practical application of powder obtained from waste, and evaluating the effectiveness of its use, complex theoretical and experimental studies are required.

The aim of the work was X-ray analysis of powder particles obtained by electro-erosion dispersion of chromium-containing wastes in lighting kerosene.

\section{Materials and techniques}

To carry out the planned research, chromium-containing steel wastes were selected. Lighting kerosene was chosen as a working fluid. To obtain a powder by the method of electroerosive dispersion, an installation for EED of conductive materials was used. Waste was loaded into a reactor filled with a working fluid - lighting kerosene; the process was carried out with the following electrical parameters: discharge capacitor capacity $45 \mu \mathrm{F}$, voltage $100 \ldots 110 \mathrm{~V}$, pulse repetition rate $55 \ldots 65 \mathrm{~Hz}$. As a result of the local impact of short-term electrical discharges between the electrodes, the waste material was destroyed with the formation of dispersed powder particles.

$\mathrm{X}$-ray microanalysis was performed using an EDAX energy dispersive X-ray analyzer embedded in a Nova NanoSEM 450 scanning electron microscope. Particles of a sample of powders were examined by scanning electron microscopy using a secondary electron detector.

Using an energy dispersive X-ray analyzer, spectra of characteristic X-ray radiation were obtained at various points on the surface of a sample of powders.

When primary electrons penetrate into the sample, they are inhibited not only by the electric field of the atoms, but also by direct collision of the atoms of the material with the electrons. As a result, the primary electrons can knock electrons from the inner K-, L- or Mshells, leaving the sample atom in an energetically excited state. Forming vacancies are filled with electron transitions from higher energy levels. The atom enters the ground state, the excess energy is emitted in the form of an x-ray quantum. Since the energy of the emerging quantum depends only on the energy of the electronic levels involved in the process, and they are characteristic of each element, characteristic X-ray radiation arises. Since each atom has a well-defined finite number of levels, between which only certain types of transitions are possible, the characteristic X-ray emission gives a discrete line spectrum.

An important characteristic of X-ray analysis is its locality, i.e. the volume of the substance in which the characteristic x-ray radiation is excited. Analysis of the distribution of elements can be performed in a qualitative, semi-quantitative and quantitative form. Qualitative analysis determines the type of elements that make up the sample area under investigation. If a sample has several phases (areas) whose chemical composition is unknown, a qualitative analysis of each phase is performed. Qualitative analysis is usually used to determine the nature of the distribution of elements over the area of thin section.

After qualitative analysis, quantitative analysis is often carried out at separately selected points; according to the obtained data, the software allows determining the type of phase on the basis of its chemical composition.

Semi-quantitative analysis is implemented if it is necessary to determine the distribution of elements along the lines (linear analysis). 
Linear analysis is performed by the step scanning method, i.e., by sequential analysis at individual points. Thus, quantitative determination of the concentration of elements with a given accuracy is carried out.

\section{Conduct X-ray analysis}

The elemental composition and microstructure of the powder of steel X13 are presented in table 1 and in figure 1.

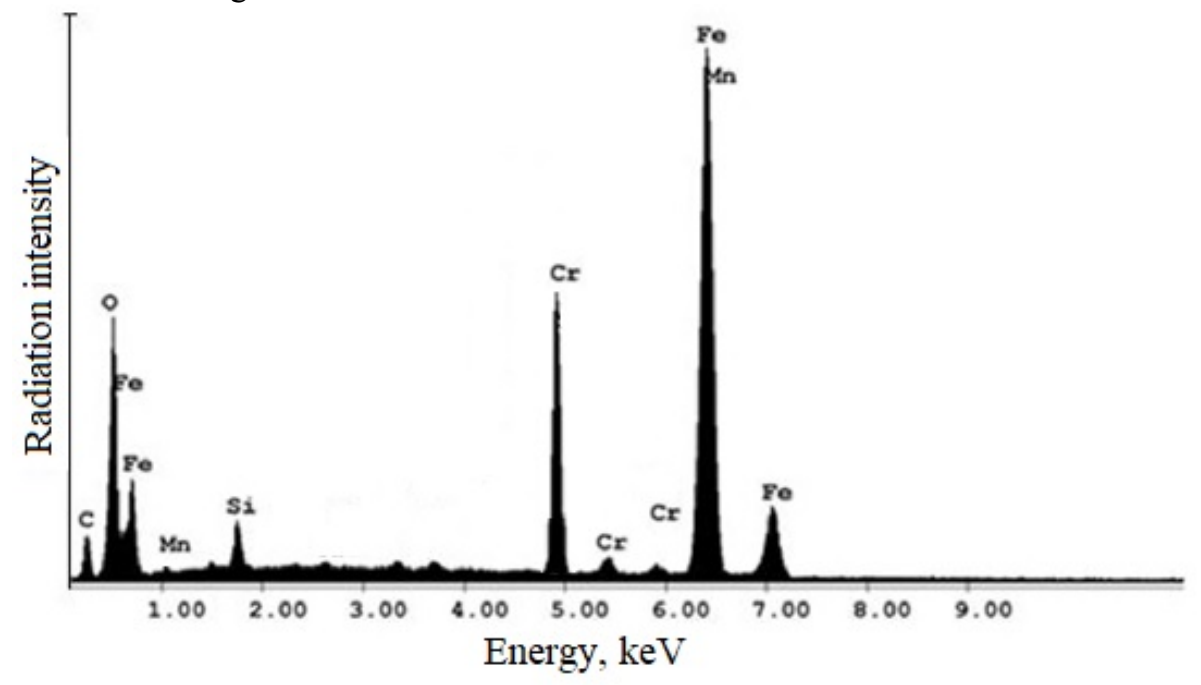

Fig. 1. Powder radiograph

Table 1. The elemental composition of powder.

\begin{tabular}{|c|c|c|}
\hline Element & $\begin{array}{c}\text { Mass } \\
\text { fraction, } \%\end{array}$ & $\begin{array}{c}\text { Atomic } \\
\text { fraction, } \%\end{array}$ \\
\hline $\mathrm{C}$ & 11,02 & 24,90 \\
\hline $\mathrm{O}$ & 2,96 & 6,86 \\
\hline $\mathrm{Si}$ & 1,89 & 2,23 \\
\hline $\mathrm{Cr}$ & 12,80 & 22,45 \\
\hline $\mathrm{Mn}$ & 0,91 & 0,55 \\
\hline $\mathrm{Fe}$ & 70,42 & 43,01 \\
\hline Total & 100,00 & 100,00 \\
\hline
\end{tabular}

The figure shows the elemental composition of the powder of steel X13, obtained by the method of EDM in lighting kerosene. The points in the figure correspond to the spectra of the characteristic $\mathrm{x}$-ray radiation. On the spectrum, each chemical element corresponds to a peak of a certain height.

\section{Conclusion}

X-ray microanalysis allowed to determine the elemental composition of the powder, obtained by electro-erosion dispersion of chromium-containing steel waste by the characteristic X-ray radiation. According to the results of the presented data, it was 
established that the main elements in the powder, obtained by the method of electroerosion dispersion of chromium-containing steel waste in lighting kerosene, are iron, oxygen, carbon and chromium. The remaining elements are distributed relatively evenly in the powder.

The work was supported by a scholarship of the President of the Russian Federation to young scientists and graduate students (SP-945.2019.1).

\section{References}

1. S.B. Maslenkov, All materials. Encyclopedic Reference No 1, 18 (2007).

2. V.A. Falkowski, F.I. Falkowski, V.S. Panov, Non-Ferrous Metal. No 10, 85 (2007).

3. T.B. Ershova, M.I. Dvornik, A.V. Zaitsev, Composite. Nanostruct. No 2, 40 (2011).

4. V.I. Tretyakov, Basics of metallurgy and production technology of sintered hard alloys (Moskow: Metallurgy: 1976).

5. N. Hertel, Ferrous Metal. No 2, 50 (2012).

6. Shishkovskii I V, Petrov A L, Makarenko A G 1999 Combustion, Explosion, and Shock Waves 35 166-170

7. E.V. Ageev, A.V. Kirichek, A.Yu. Altuhov, E.V. Ageeva, J. Nano- Electron. Phys. 6 No 3, 03001 (2014).

8. E.V. Ageeva, E.V. Ageev, N.M. Horyakova, V.S. Malukhov, J. Nano- Electron. Phys. 6 No 3, 03011 (2014).

9. E.V. Ageeva, E.V. Ageev, V.Yu. Karpenko, A.S. Osminina, J. Nano- Electron. Phys. 6 No 3, 03049 (2014).

10.E.V. Ageev, The patent 2449859, the Russian Federation, C2, B22F9/14. No 2010104316/02; appl. 08.02.2010; publ. 10.05.2012. - 4 p. 